University of Louisville

ThinkIR: The University of Louisville's Institutional Repository

Faculty Scholarship

2013

\title{
The role of self-transcendence : a missing variable in the pursuit of successful aging?
}

Valerie Lander McCarthy

University of Louisville, valerie.mccarthy@louisville.edu

Jiying Ling

University of Louisville

Robert M. Carini

University of Louisville

Follow this and additional works at: https://ir.library.louisville.edu/faculty

Part of the Gerontology Commons, and the Nursing Commons

\section{Original Publication Information}

This is a pre-copy-editing, author-produced PDF of an article accepted for publication in Research in Gerontological Nursing, volume 6, number 3, in 2013, following peer review. The definitive publisherauthenticated version is available online at DOI: 10.3928/19404921-20130508-01

This Article is brought to you for free and open access by ThinkIR: The University of Louisville's Institutional Repository. It has been accepted for inclusion in Faculty Scholarship by an authorized administrator of ThinkIR: The University of Louisville's Institutional Repository. For more information, please contact thinkir@louisville.edu. 
The Role of Self-Transcendence: A Missing Variable in the Pursuit of Successful Aging?

Valerie Lander McCarthy, PhD, RN, Jiying Ling, MS, PhD, and Robert M. Carini, PhD

University of Louisville

(2013). Research in Gerontological Nursing, 6(3), 178-186. Doi: 10.3928/19404921-2013050801.

Corresponding Author:

Valerie Lander McCarthy, PhD, RN

4036 K-Bldg., Health Science Campus

University of Louisville School of Nursing

Louisville, KY 40292

$1-502-819-5037$

vemcca01@louisville.edu

Author's Note: The authors wish to thank the University of Louisville Office of the Executive Vice President for research funding for this study through an Intramural Research Initiation Grant.

McCarthy Bio: Valerie Lander McCarthy, $\mathrm{PhD}, \mathrm{RN}$ is an assistant professor at the University of Louisville. A community health nurse, McCarthy researches successful aging and transcendence. She was selected as a 2011 Hartford Summer Scholar.

Ling Bio: Jiying Ling, MS is a doctoral candidate in the School of Nursing at the University of Louisville and has completed a Master's degree in statistics.

j0ling02@louisville.edu.

Carini Bio: Robert M. Carini, $\mathrm{PhD}$ is associate professor in sociology at the University of Louisville. He was co-recipient of the American Sociological Association's 2007 Outstanding Publication Award (Section on Aging and the Lifecourse) and researches leisure and recreation. rmcari01@louisville.edu. 


\begin{abstract}
Background: While successful aging is often defined as the absence of disease and disability or as life satisfaction, self-transcendence may also play an important role.

Objective: To test a nursing theory of successful aging proposing transcendence and adaptation predict successful aging.

Method: A cross-sectional exploratory study $(N=152)$ among a convenience sample of older adults were surveyed about self-transcendence, proactive coping, and successful aging. Results: Using hierarchical multiple regression, self-transcendence, proactive coping, and all controls (sex, race, health and residence) together explained $50 \%$ of the variance in successful aging" $(p<.001)$. However, proactive coping was not a significant predictor of successful aging. Discussion: This study did not support the theory that both self-transcendence and proactive coping predict successful aging. Self-transcendence was the only significant contributor to this multidimensional view of successful aging. Self-transcendence is an important variable in the pursuit of successful aging which merits further investigation.
\end{abstract}




\section{The Role of Self-Transcendence: A Missing Variable in the Pursuit of Successful Aging?}

At least since the early 1960s, research in multiple fields has examined various definitions and criteria for successful aging. While life satisfaction, health, function, and social engagement have been shown to be important criteria for successful aging, variables within the spiritual or existential domain have received considerably less attention. Two prior studies among older adults in residential retirement facilities have suggested self-transcendence, an inherent developmental process which shapes how older adults see themselves, others, God or a higher power, and the nature of life itself, may be an important contributor to successful aging. This exploratory cross-sectional survey study followed-up on the prior studies to explore the role of self-transcendence among non-demented adults, aged 65 and older, living in the community as well as in a retirement facility. Findings support the potential importance of self-transcendence in the pursuit of understanding and promoting successful aging among the rapidly increasing numbers of older adults.

\section{Background}

Successful aging means many things to many people and is often used synonymously with other terms such as healthy aging, optimal aging, positive aging, and aging well (Peel, Bartlett, \& McClure, 2004). The first use of the term successful aging is attributed to Havighurst (1961) but the idea gained attention among the lay public and generated significant aging research in 1998 when Rowe and Kahn defined successful aging as low risk of chronic disease, independent physical and cognitive function, and productive engagement with life.

While Rowe and Kahn's (1998) definition of successful aging was an important contribution to how aging was viewed, it was also problematic for a number of reasons. First, Rowe and Kahn's definition excluded those with any degree of chronic disease, disability, or decreased function (Schulz, \& Heckhausen, 1996). Second, older adults' own views on what 
constituted "success" were not considered (Phelan, Anderson, LaCroix, \& Larson, 2004) and researchers' definitions were not congruent with those of older adults (Strawbridge et al., 2002). Moreover, Holstein and Minkler (2003) pointed out that Rowe and Kahn's (1998) criteria for successful aging focused on lifestyle and behavioral determinants of health, but did not take into account social and environmental factors that also affect health, thus limiting the potential for success among minority and socioeconomically disadvantaged populations.

\section{Linkages between Successful Aging and Spirituality}

Crowther and her colleagues (Crowther, Parker, Achenbaum, Larimore, \& Koenig, 2002) and others (Sadler \& Biggs, 2006) pointed out that Rowe and Kahn's (1998) and most other definitions of successful aging fail to consider criteria for successful aging within the spiritual domain. Crowther et al. noted the link between spirituality, health, and well-being among older adults, and, hoping to call attention to this important criterion for successful aging among health professionals, religious organizations, and governmental agencies, advocated that interventions to improve health targeted toward underserved populations should include spirituality.

There is often confusion regarding the distinction between religion and spirituality (Crowther et al., 2002). According to Koenig and his colleagues, religion does not involve only God or a deity; it also encompasses a shared system of beliefs, rituals, moral standards and social rules. Spirituality is defined more broadly as a search more answers to existential questions about the meaning of life and the individual's relationship to the sacred or transcendent (Koenig et al. 2000) which may or may not involve affiliation with a specific religion. It is this broad concept of spirituality that is integral to nursing and it is this view of spirituality that was adopted for the present study. 


\section{The Concept of Transcendence}

Transcendence is a concept within the spiritual domain that has been linked to successful aging in developmental psychology and life span development theory (Erikson \& Erikson, 1997; Jung, 1972; Maslow, 1971; Peck, 1968). Maslow (1969) defined transcendence as rising above or moving beyond time, culture, self, and others. Transcendent behaviors described by Maslow included: moving beyond weaknesses, fears, and dependency; living one's life regardless of the opinions or expectations of others, such as social conventions, family roles, or a focus on others to the exclusion of self; and achieving a sense of unity with the self, nature, others - especially the next generation - and a higher power or dimension greater than the self.

Erikson (Erikson \& Erikson, 1997) wrote about transcendence as an additional developmental stage in very late life, beyond the original final stage of ego integrity versus despair. Peck (1968) re-worked Erikson's stages to define three developmental tasks for older adults: (1) role transcendence versus role preoccupation, (2) body transcendence verses body preoccupation, and (3) ego transcendence versus ego preoccupation. In the first task, older adults must find meaningful activities that create a sense of self-worth outside of career or professional identity. In the second task, body transcendence refers not to ignoring or neglecting bodily concerns, but instead to finding joy and meaning in life despite disease and functional limitations. The third task closely approximates Erikson's definition of ego integrity, i.e., accepting the nearness of death by finding satisfaction and meaning in one's life accomplishments.

Tornstam (2005) proposed gerotranscendence as a final stage in a natural progression towards maturation and wisdom marked by a sudden shift from a materialistic and rational view of the world to a more cosmic viewpoint with greater acceptance of self and others, increased 
selectivity of relationships and activities based on personal choices rather than social expectations, greater need for solitude, decreased fear of death, and increased life satisfaction.

A similar concept, self-transcendence, was described by Reed (2003) in a mid-range nursing Theory of Self-transcendence. Reed defined self-transcendence as an inherent, gradual, nonlinear developmental process, resulting in increased awareness of dimensions greater than the self and expansion of personal boundaries within intrapersonal, interpersonal, transpersonal and temporal domains. Reed stated self-transcendence was evidenced by greater self-acceptance, a focus on finding meaning, reaching out to others, openness to a higher entity or purpose, and understanding one's past and future to make sense of the present (Reed, 2009). Reed (2003) contended that with the development of self-transcendence older adults view the world more contextually, more easily tolerate ambiguity and the paradoxes inherent in life, and demonstrate a greater awareness of the spiritual and existential domain. Reed (2003) pointed out that while transcendence is often interpreted as going above and beyond the everyday, in her view selftranscendence also, "embodies experiences that connect rather than separate a person from self, others, and the environment" (p. 147). Specific behaviors that may promote the development of self-transcendence included altruistic activities such as volunteer service, time spent in reflection on spiritual or existential beliefs, lifelong learning, creativity, journaling, and intergenerational relationships which allow passing on wisdom gained through accumulated knowledge and experience (Reed, 2009).

A recent concept analysis of transcendence identified essential attributes of transcendence drawn from a review of literature from multiple disciplines, and synthesized a definition of transcendence as an inherent developmental process resulting in a shift in perspective from a rational, materialistic view to a wider world view characterized by broadened personal boundaries within interpersonal, intrapersonal, transpersonal and temporal dimensions, resulting 
in increased sense of meaning in life, well-being, and life satisfaction (McCarthy \& Bockweg, 2012a). A conceptual model was developed that organized precursors and attributes of transcendence within five domains: contemplation, introspection, spirituality, creativity, and relationships.

\section{A Nursing View of Transcendence and Successful Aging}

Another mid-range nursing theory, the Theory of Successful Aging (Flood, 2006), directly linked the concept of transcendence to successful aging. Flood defined successful aging as, "a favorable outcome as perceived by the individual, and his ability to cope and adapt to the cumulative changes associated with the passage of time, while experiencing a sense of meaning or purpose in life" (Flood, 2003, p. 105). The theory proposed gerotranscendence and adaptation as coping mechanisms which lead to this view of successful aging.

Two prior studies (McCarthy, 2009, 2011) found support for Flood's (2006) proposition that self-transcendence and adaptation predict successful aging. In both studies, selftranscendence was measured using Reed's Self-transcendence Scale (1989a), and adaptation was operationalized as proactive coping (Greenglass, et al., 1999). The Successful Aging Inventory, recently developed by Troutman (see Flood) was used to measure the outcome variable (Troutman, Nies, Small \& Bates, 2011). The first of these two prior studies was a pilot study among a convenience sample $(N=20)$ of non-demented adults, aged 65 and older, living in a retirement community. Despite the small sample size, when successful aging was regressed on self-transcendence and proactive coping, a significant model explained $37 \%(p<.05)$ of the variance in successful aging. What was more surprising, given the known importance of adaptation and coping, was that when standardized regression coefficients were examined, selftranscendence $(\beta=.50)$ explained a greater proportion of the variance than was explained by proactive coping $(\beta=.28)$. A subsequent study among a random sample of older adults $(N=$ 
123) in a larger retirement community found that self-transcendence and proactive coping explained $45 \%(p<.05)$ of the variance in successful aging, with self-transcendence $(\beta=.52)$ again contributing more of the effect on successful aging than proactive coping $(\beta=.20)$.

\section{Aims of the Present Study}

The primary purpose of this exploratory cross-sectional survey study was to follow-up on the prior studies among a larger, more diverse sample in a mid-sized Southern city. A secondary purpose was to investigate the convergent validity of the Likert-type version of the primary

outcome measure, the Successful Aging Inventory (SAI) (Troutman, Nies, Small \& Bates, 2011), by comparison with a commonly used measure for successful aging based on a revision of the Life Satisfaction Index-A (Neugarten, Havighurst, \& Tobin, 1961), i.e., the Life Satisfaction Index for the Third Age, Short Form (LSITA-SF) (Barrett \& Murk, 2009).

Specific aims of the study included:

Aim 1. To determine if self-transcendence and proactive coping explain a significant proportion of the variance in successful aging among non-demented adults, aged 65 and older, living in the community or in a residential retirement facility.

Aim 2. To determine if self-transcendence explains a greater proportion of the variance in successful aging than proactive coping.

Aim 3. To examine convergent validity for the Successful Aging Inventory (SAI) through a significant correlation of the SAI with the Life Satisfaction Index for the Third Age (LSITA) (Barrett \& Murk, 2009).

\section{Methods}

An exploratory, cross-sectional survey study design was used to examine relationships among the two independent variables, self-transcendence and proactive coping, and the outcome 
variable, successful aging, controlling for age, sex, race, self-reported health, and place of residence.

\section{Setting \& Sample}

Following approval by the university’s Institutional Review Board and letters of agreement with three data collection sites, a convenience sample of non-demented adults, aged 65 and older, was drawn from residents of (a) a residential retirement community $(n=51)$ and from two senior citizen centers, (b) one in a moderate-income, largely white neighborhood $(n=$ 52), and the other in (c) a low-income African American neighborhood $(n=49)$. The retirement community provided both independent housing and assisted living services such as help with bathing, dressing and hygiene and supervision of self-administered medications. Both senior citizen centers provided recreational activities for active, mobile older adults; the low-income center also was a designated meal site and provided social service referral.

A convenience sample $(N=152)$ was recruited by posting flyers and speaking at regularly scheduled meetings and gatherings at the retirement community and the senior citizen centers. Inclusion criteria were: adult aged 65 or older; normal score on the Mini-Cog Dementia Test (Borson, Scanlan, Brush, Vitaliano, \& Dokmak, 2000); and the ability to complete the data collection process with accommodations for sensory or literacy deficits. The Mini-Cog is a brief (approximately 3 minutes) screening tool designed to identify those with dementia. The test uses a three-item recall exercise and a clock-drawing test and has been validated among older adults with various language, culture and literacy levels in clinical and community settings. Potential participants were advised about dementia testing prior to written informed consent.

\section{Measurement Instruments}

Standardized questionnaires were used to measure the outcome variable, successful aging, and the two predictor variables, self-transcendence and proactive coping. Demographic 
variables and potential covariates (age, sex, race, income level, marital status, education, selfreported health, place of residence) were self-reported using an investigator-developed questionnaire. A well-validated measure of life satisfaction was used to establish convergent validity with the recently developed measure of successful aging. A description of each measurement instrument, with means, standard deviations and Cronbach's alphas may be found in Table 1.

\section{-- Insert Table 1 about here -}

Aging outcomes. Successful aging was the primary outcome variable and was measured via a summative index using 20 items from the recently developed Successful Aging Inventory (SAI) (Troutman, et al., 2011). The SAI was developed among community-dwelling older adults attending a senior citizen center, to capture the new view of successful aging. Items employ a five-point response scale with choices ranging from "hardly ever" to "almost always". Troutman reported a Cronbach's alpha coefficient of .88 and convergent validity with three similar scales. Test/re-test stability among older adults in retirement communities was demonstrated by alpha coefficients of .72 (McCarthy, 2009) and .82 (McCarthy, 2011). For our sample, we computed a Cronbach's alpha coefficient of .84.

Life satisfaction was added as a second aging outcome to investigate convergent validity through correlation with the SAI. The Life Satisfaction Index for the Third Age-Short Version (LSITA-SF) (Barrett \& Murk, 2009) is a 12-item summative scale based on Neugarten's Life Satisfaction Index-A (LSI-A) (Neugarten, et al., 1961) and is designed to measure overall life satisfaction among older adults. The LSITA-SF was adapted from the LSI-A to develop an 
updated instrument with improved psychometric properties. The LSITA-SF employs a six-point Likert-style response scale with choices ranging from "strongly disagree" to "strongly agree". Strong psychometric properties were found for the LSITA-SF, with a Cronbach's alpha coefficient of almost .90 and high correlations (> .70) with two criteria scales (criteria validity), as well as an excellent goodness of fit score in Confirmatory Factor Analysis (construct validity). Item scoring, as suggested by Barrett and Murk (2009), results in higher scores denoting more dissatisfaction. Instead, we coded each item so that higher scores signaled more life satisfaction, and then summed the 12 item scores to create a unidimensional index. A Cronbach's alpha coefficient of .86 was calculated for the scale.

Key independent variables. Self-Transcendence was measured using Reed's Selftranscendence Scale (STS) (1989a), originally developed among both older adults and terminally ill adults. The STS consists of 15 items on a four-point scale which measure older adults' perceptions of transcendence, ranging from 1 for "not at all" to 4 for "very much". Coward (1990) reported Cronbach's alpha coefficients from .80 to .88 for the STS, with test/retest stability of .70 to .95 . In our study, Cronbach's alpha coefficient was .78.

Adaptation was operationalized with the Proactive Coping Subscale (PCS) of the Proactive Coping Inventory (Greenglass, et al., 1999). The Proactive Aging Subscale measures coping not only in response to immediate stressors but also building up resources in advance for anticipated future stressors and considers both the challenges and the opportunities of late life. The unidimensional PCS consists of items on a four-point scale, ranging from "not at all true" to "completely true". The PCS is well validated among older adults, with internal consistency in other studies reported in the .80 to .85 range. Cronbach's alpha coefficient was .73 for the present study. 
Covariates. Demographic variables and potential covariates were measured using selfreport information from the investigator-developed questionnaire. Covariates entered in multiple regression models that predicted successful aging were: age, sex, race, self-reported health, and place of residence. Age was measured in years, and analyzed both as a continuous variable and as a categorical variable $(65-69 ; 70-79 ; 80+)$. Place of residence was a dichotomous variable, coded as " 1 " for community-dwelling respondents and " 0 " for those living in a residential retirement community. Health was measured via the question: "How would you describe your overall health?" Responses were coded from 1 = "poor" to 4 = "very good".

\section{Procedure}

Data collection in this study and two prior studies was described in a previous publication (McCarthy \& Cassidy, 2012b). Briefly, in all three studies participants were recruited at residential retirement communities or senior centers. In each of these studies, including the present study, following written informed consent, survey data were collected among small groups $(n=5-8)$, using a standardized protocol to maintain independence of responses and participants' privacy, while accommodating for sensory and literacy limitations. All participants completed consent, dementia screening and the set of questionnaires in a single session, but only data from non-demented participants were included in data analysis, as explained in the consent process.

Correlations among variables were measured using Pearson's $r$ tests for two continuous variables; Phi coefficient for one continuous and one categorical variable; and Point-biserial for two categorical variables. Two-sample independent t-test was used to assess group differences in successful aging when the group variable had two levels. Two-tailed tests were considered significant at the level of .05 or lower. The mid-range nursing theory of successful aging provided a basis for hierarchical multiple regression and ordinary least squares regressions which 
were run using the Statistical Package for Social Science (SPSS) Version 21; R 2.15.1 was also used for model comparison. In step one, control variables (age, sex, race, place of residence and perceived health) were entered as predictors of successful aging. In the next step, successful aging was regressed onto self-transcendence and proactive coping, controlling for age, sex, race, place of residence and perceived health, using backward selection. Casewise deletion was applied to deal with missing data. In the last step, proactive coping was removed from the model and successful aging was regressed on self-transcendence, still controlling for age, sex, race, place of residence and perceived health.

\section{Results}

The sample ranged from 65 to 102 years old $(M=79.58)$ and was mostly female $(79 \%)$. Racial composition was $66 \%$ white and 34\% African American. The vast majority were either married $(32 \%)$ or widowed (47\%) with $19 \%$ divorced or separated. Few made more than $\$ 60,000$ annually (10\%). Almost half of the sample reported annual incomes of less than $\$ 25,000$ and $40 \%$ between $\$ 25,000$ and $\$ 60,000$. Most had at least a high school education (83\%); with a majority having at least some college education (54\%). Most individuals self-described themselves as having good or very good health (72\%) and self-reported that they were aging successfully (96\%). Our analytic sample size decreased from 152 to 132 once missing values on one or more variables were removed.

Self-transcendence $(r=.69)$ and proactive coping $(r=.45)$ were both significantly correlated with successful aging, as was health $(r=.27)$ and age $(r=-.35)$. When age was measured as a categorical variable, the correlation of successful aging with age 70 to 79 was not significant $(r=-.11)$, but successful aging was significantly correlated with age 80 years and older $(r=-.29)$. African Americans perceived more successful aging than Caucasians $(M=67.91$ vs. $\left.64.12, t_{130}=-2.35, p=.02\right)$, and women perceived more successful aging than men $(M=66.31$ vs. 
$\left.62.07, t_{130}=2.25, p=.026\right)$. Moreover, older adults living in the community reported aging more successfully than those living in a retirement community $\left(M=67.37\right.$ vs. $61.35, t_{65}=3.43, p=$ $.001)$. As expected, the two predictors were strongly correlated $(r=.55)$ but not redundant in what they were measuring.

The results of the analysis to answer the first specific aim are displayed in Table 2 which provides hierarchical regression models for the outcome of successful aging, controlling for age, race, sex, health and place of residence. Results are reported conservatively, using Adjusted $R^{2}$ values. In the three models, the tolerance values for all the independent variables were greater than .10, suggesting multicollinearity was not a problem in the regression analysis. The DurbinWatson statistic was in the acceptable range of 1.50 to 2.50 , indicating that errors (residuals) were independent and there was no serial correlation.

\section{-- Insert Table 2 about here -}

As shown in Model 1, demographic (control) variables explained 24\% of the variance in successful aging $(p<.001)$, and age, sex, and perceived health were all significant contributors to successful aging. Model 2 added self-transcendence and proactive coping as predictors. This model explained $50 \%$ of the variability in successful aging $(p<.001)$, and the model fit was significantly improved compared to Model $1\left(F_{2,124}=34.97, p<.001\right)$. Self-transcendence was the only significant contributor to successful aging $(\beta=.56, p<.001)$, after controlling for age, race, sex, perceived health and place of residence. Proactive coping was not a significant contributor to successful aging in Model 2 and was removed in Model 3, leaving selftranscendence and the controls. The adjusted R-square statistic for Model 3, labeled 'trimmed 
model', rose slightly to .51 , with the fit for the trimmed model not being significantly different than for Model $2(\mathrm{~F} 1,124=0.56, \mathrm{p}=0.46)$. Specific aim two, to determine if self-transcendence explains a greater proportion of the variance in successful aging than proactive coping, was answered by examining bivariate regression coefficients to assess the contributions of individual variable to levels of successful aging. Self-transcendence alone explained $47 \%(p<.001)$ of the variance in successful aging, while proactive coping explained only $20 \%(p<.001)$ of the variability in successful aging. Using Fisher r-to-z transformation, self-transcendence was found to explain a significantly greater proportion of the variance in successful aging than proactive coping $\left(Z_{132}=2.92, p=.004\right)$.

The final specific aim was to examine the correlation of the SAI (Troutman, Nies, Small \& Bates, 2011) with the LSITA-SF (Barrett \& Murk, 2009) to evaluate convergent validity for the (SAI). The SAI was significantly correlated with the LSITA-SF as evidenced by a Pearson's $r$ of .62 $(p<.05)$ and congruence was noted between the SAI and the LSITA-SF in relationship to proactive coping and self-transcendence.

\section{Discussion}

Results did not support the proposition that self-transcendence and proactive coping are significant predictors of a holistic view of successful aging. While Flood's theory (2006) was supported in two previous studies conducted in moderate- and low-income retirement communities (McCarthy, 2009; 2011), in both of those studies self-transcendence explained a significantly greater proportion of the variance in successful aging. The present study demonstrated that while self-transcendence and proactive coping, together with controls, did significantly predict successful aging. However, as shown in Model 2, proactive coping did not significantly contribute to the variance in successful aging. It is apparent that self-transcendence is the major contributor to successful aging among community-dwelling older adults and those 
living in a residential retirement community. Thus self-transcendence, not previously studied in relationship to successful aging, merits further investigation.

Other studies of self-transcendence have examined associations with depression among older adults (Reed, 1989b, 1991) and depression in middle-aged adults (Ellerman \& Reed, 2001). Self-transcendence has consistently been correlated with well-being in samples with advanced breast cancer (Coward, 1990, 1991), HIV/AIDS (Coward, 1995) and terminally ill hospitalized adults (Reed, 1987) as well as in dementia caregivers (Acton, 2002) and a healthy middle-aged population (Coward, 1996).

However, with the exception of Imperio (2006), the majority of studies of transcendence have focused on the relationship of self-transcendence to illness or loss rather than on a multidimensional, positive view of aging. The literature reflects little investigation of how selftranscendence might shape successful aging among community-dwelling older adults or those living in retirement communities. Perhaps because participants living in a retirement community were lower on these desirable measures to start with, they had more to gain than did community dwellers.

To address the final specific aim, a significant correlation $(r=.62)$ between successful aging, measured using the Successful Aging Inventory (SAI) (Troutman, et al., 2011), and a measure of life satisfaction (LSITA-SF) (Barrett \& Murk, 2009), as well as congruence between the SAI and the LSITA-SF in relationship to proactive coping and self-transcendence provided evidence of convergent validity for the SAI. Reliability of the SAI was indicated by a Cronbach's alpha coefficient of .84 compared to an alpha coefficient of .88 obtained in instrument development as well as alpha coefficients of .72 and .82 in prior studies (McCarthy, 2009, 2011). 
Limitations of this study include the use of self-report data and the potential for social desirability bias, which was partially addressed through use of a strictly standardized protocol and items on questionnaires with responses which were not obviously more or less socially acceptable. Also, self-selection bias and an associated ceiling effect existed. It is reasonable to assume only more functional and motivated older adults would be available and consent to participate in the study, as evidenced by the very high percentage of those who claim to be aging successfully. Future studies should include larger and more varied samples, perhaps including participants who are home-bound or residents of nursing homes, to assess the potential for successful aging in less healthy, active elders.

In addition, the cross-sectional design of the study provides only a "snapshot in time"; longitudinal study is necessary to determine if these findings will persist over time. Most importantly, the specific nature of relationships between self-transcendence and successful aging remains unknown; whether one factor mediates or moderates another is undetermined; and no causality can be implied by the cross-sectional findings. It is possible that self-transcendence, with or without the effect of proactive coping, may promote successful aging. It is also possible that successful aging and/or proactive coping may encourage development of self-transcendence.

Future research is needed to explore whether a self-transcendence-based intervention may increase levels of self-transcendence and other beneficial outcomes such as well-being, life satisfaction. Consistent correlations of self-transcendence with increased well-being, life satisfaction, and acceptance of life situations have been demonstrated, as well as with decreased levels of depression, perceived pain, and caregiver stress. An intervention study is needed to explore the possibility that self-transcendence is a modifiable factor and that increases in levels of self-transcendence are significantly related to increases in other beneficial outcomes. For instance a program to encourage creativity, introspective and altruistic activities, and spiritual 
perspectives may help a person transcend difficulties, including losses associated with aging. In particular, vulnerable populations may benefit from holistic practices such as meditation, prayer, and visualization, to assist in finding meaning and purpose in life, a sense of well-being, and improved quality of life (Teixeira, 2008).

Findings of this study suggest self-transcendence may be an important concept in a holistic view of successful aging. Evidence suggests self-transcendence may be a modifiable factor with the potential for effective interventions that would not require extensive use of human and financial resources and potentially might improve quality of life for not only for white, wealthy and well-educated older adults but also those with disease, disability and socioeconomic disadvantages. 


\section{References}

Acton, G. J. (2002). Self-transcendent views and behaviors: Exploring growth in caregivers of adults with dementia. Journal of Gerontological Nursing, 28(12), 22-30. PMID: 12567823

Barrett, A. J. \& Murk, P. J. (2009). Life Satisfaction Index for the Third Age-Short Form (LSITA-SF): An improved and briefer measure of successful aging. Presented at the Midwest Research-to-Practice Conference in Adult, Continuing, Community and Extension Education, Northeastern Illinois University, Chicago, IL, October 21-23. Obtained online on May 2, 2010 at http://www.neiu.edu/ hrd/mwr2p09/Papers/Barrett.pdf

Borson, S., Scanlan, J., Brush, M., Vitaliano, P., \& Dokmak, A. (2000). The Mini-cog: A cognitive 'vital signs' measure for dementia screening in multi-lingual elderly. International Journal of Geriatric Psychiatry, 15(11), 1021-1027. DOI: 10.1002/10991166(200011)15

Coward, D. (1990). The lived experience of self-transcendence in women with advanced breast cancer. Nursing Science Quarterly, 3, 162-169. DOI: 10.1177/089431849000300408

Coward, D. (1991). Self-transcendence and emotional well-being in women with advanced breast cancer. Oncology Nursing Forum, 18, 857-863. PMID: 1891414

Coward, D. (1995). The lived experience of self-transcendence in women with AIDS. Journal of Obstetric, Gynecologic, and Neonatal Nursing, 24, 314-318. DOI: 10.1111/j.15526909.1995.tb02482.x

Coward, D. (1996). Self-transcendence and correlates in a healthy population. Nursing Research, 45, 116-122. PMID: 8604361 (Mot available online from the journal)

Crowther, M. R., Parker, M. W., Achenbaum, W. A., Larimore, W. L., \& Koenig, H. G. (2002). Rowe and Kahn's model of successful aging revisited: Positive spirituality - the forgotten factor. The Gerontologist, 42(5): 613-620. DOI: 10.1093/geront/42.5.613

Ellerman, C. R. \& Reed, P. G. (2001). Self-Transcendence and depression in middle-age adults. Western Journal of Nursing Research, 23(7), 698-713. DOI:

$10.1177 / 01939450122045492$

Erikson, E. H. \& Erikson, J. M. (1997). The life cycle completed: Extended version with new chapters on the ninth stage of development. New York: W. W. Norton and Company, Inc. 
Flood, M. (2006). A mid-range theory of successful aging. Journal of Theory Construction and Testing, 9(2), 35-39.

Greenglass, E., Schwarzer, R., Jakubiec, D., Fiksenbaum, L., \& Taubert, S. (1999). The Proactive Coping Inventory (PCS): A multidimensional research instrument. [Technical report.] Retrieved online April 9, 2008 at http://www.psych.yorku.ca/greenglass/pci.php

Havighurst, R. (1961). Successful aging. The Gerontologist, 1, 8-13. DOI:10.1093/geront/1.1.8 Holstein, M. B., \& Minkler, M. (2003). Self, society, and the "new gerontology." The Gerontologist, 43(6), 787-796. DOI:10.1093/geront/43.6.787

Imperio, K. (2006). Transcendence in successful aging: A grounded theory of older women's strategies to age successfully. Electronic Doctoral Dissertations for UMass Amherst. Paper AAI3216953. http://scholarworks.umass.edu/dissertations/AAI3216953.

Jung, C. G. (1972). The transcendent function. In the structure and dynamics of the psyche: Volume 8. The collected works of C. G. Jung ( $2^{\text {nd }}$ ed.). H. Read, M. Fordham, G. Adler, \& W. McGuire Eds.). London: Routledge and Kegan Paul.

Koenig H. G., McCullough M., Larson D. B. (2000). Handbook of religion and health. Oxford University Press, New York.

Maslow, A. (1969). Various meanings of transcendence. Journal of Transpersonal Psychology, $1,56-66$.

Maslow, A. (1971). The Farther Reaches of Human Nature. New York: Viking Press.

McCarthy, V. L. (2009). A feasibility study: Exploring the relationship of transcendence and adaptation with a new view of successful aging. Poster presentation for Research!Louisville Annual Research Conference. October 12 - 16. Louisville. KY.

McCarthy, V. L. (2011). A new look at successful aging: Exploring a mid-range nursing theory among older adults in a low-income retirement community. Journal of Theory Construction and Testing, 15(1), 17-21.

McCarthy, V. L. \& Bockweg, M. (2012a). The role of transcendence in a holistic view of successful aging: A concept analysis and model of transcendence in maturation and aging. Journal of Holistic Nursing, Early Online. DOI: 10.1177/0898010112463492 
McCarthy, V. L. \& Cassidy, K. (2012b). Multisite recruitment and data collection among older adults: Exploring methods to conserve human and financial resources. Journal of Nursing Measurement, 20(2). 142-152. DOI: 10.1891/1061-3749.20.2.142

Neugarten, B. L., Havighurst, R. J., \& Tobin, S. S. (1961). The measurement of life satisfaction. Journal of Gerontology, 16, 134-143. DOI: 10.1093/geronj/16.2.134

Peck, R. (1968). Psychological developments in the second half of life. In B. Neugarten (Ed.). Middle age and aging. Chicago: Chicago University Press.

Peel, N. M., Bartlett, H. P., \& McClure, R. J. (2004). Healthy ageing: How is it defined and measured? Australian Journal on Ageing, 23(3), 115-119. DOI:10.1093/ageing/afm120

Phelan, E. A., Anderson, L. A., LaCroix, A. Z., \& Larson, E. B. (2004). Older adults' views of "successful aging": How do they compare with researchers' definitions? Journal of the American Geriatrics Society, 52, 211-216. DOI: 10.1111/j.1532-5415.2004.52056.x

Reed. P. G. (1987). Spirituality and well-being in terminally ill hospitalized adults. Research in Nursing and Health, 10, 335-344. PMID: 3671781

Reed. P. G. (1989a). Self-transcendence in aging scale: Mental health of older adults. Western Journal of Nursing Research, 11(2), 161-163. DOI: 10.1177/019394598901100202

Reed. P. G. (1989b). Mental health of older adults. Western Journal of Nursing Research, 11, 143-163. DOI: 10.1177/019394598901100202

Reed, P. G. (1991). Self-transcendence and mental health in oldest-old adults. Nursing Research, 40(I), 5-11. PMID:1987557

Reed, P. G. (2003). The theory of self-transcendence. In P. R. M. J. Smith and Liehr (Ed.), Middle Range Theory for Nursing (pp. 145-165). New York: Springer Publications.

Reed, P. G. (2009). Demystifying self-transcendence for mental health nursing practice and research. Archives of Psychiatric Nursing, 23(5), 397-400. DOI: 10.1016/j.apnu.2009.06.006

Rowe, J., \& Kahn, R. (1998). Successful aging. New York: Random House.

Sadler, E., \& Biggs, S. (2006). Exploring the links between spirituality and 'successful aging'. Journal of Social Work Practice, 20(3), 267-280. DOI: 10.1080/02650530600931757

Schulz, R. \& Heckhausen, J. (1996). A life span model of successful aging. American Psychologist, 51(7), 702-714. DOI: 10.1037/0003-066X.51.7.702 
Strawbridge, W. J., Wallhagen, M., \& Cohen, R. (2002). Successful aging and well-being: Selfrated compared with Rowe and Kahn. The Gerontologist, 42, 727-733. DOI: 10.1093/geront/42.6.727

Teixeira, M. E. (2008). Self-transcendence: A concept analysis for nursing praxis. Holistic Nursing Practice, 22(1), 25-31. DOI: 10.1097/01.HNP.0000306325.49332.ed

Tornstam, L. (2005). Gerotranscendence: A developmental theory. New York: Springer Publishing.

Troutman, M., Nies, M. A., Small, S., \& Bates, A. (2011). The development and testing of an instrument to measure successful aging. Research in Gerontological Nursing, 4(3), 221 232. DOI: $10.3928 / 19404921-20110106-02$ 
Table 1. Means and Standard Deviations for Successful Aging, Life Satisfaction, Self-Transcendence, and Proactive Coping $(\mathrm{N}=132)$

\begin{tabular}{|c|c|c|c|c|c|}
\hline Measure & Instrument & Metric & Mean & $\mathrm{SD}$ & $\begin{array}{c}\text { Cronbach's } \\
\text { alpha }\end{array}$ \\
\hline \multicolumn{6}{|l|}{ Aging Outcomes } \\
\hline$\overline{\text { Successful Aging }}$ & $\begin{array}{l}\text { Successful Aging Inventory } \\
\text { (SAI) (Troutman, Nies, Small, \& } \\
\text { Bates, 2011) }\end{array}$ & $\begin{array}{l}\text { 20-item scale } \\
(0=\text { "hardly ever" to } \\
80=\text { "almost always") }\end{array}$ & 65.41 & 8.96 & .84 \\
\hline Life Satisfaction & $\begin{array}{l}\text { Life Satisfaction for the Third } \\
\text { Age Scale-Short Form (LSI-TA) } \\
\text { (Barrett and Murk, 2009) }\end{array}$ & $\begin{array}{l}12-\text { item scale } \\
(12=\text { "strongly disagree" to } \\
72=\text { "strongly agree") }\end{array}$ & 51.66 & 8.98 & .86 \\
\hline \multicolumn{6}{|l|}{$\underline{\text { Key Predictors }}$} \\
\hline Self-Transcendence & $\begin{array}{l}\text { Self-Transcendence Scale (STS) } \\
\text { (Reed, 1989a) }\end{array}$ & $\begin{array}{l}15 \text {-item scale } \\
(15=\text { "not at all" to } \\
60=\text { "very much") }\end{array}$ & 53.07 & 4.67 & .78 \\
\hline Proactive coping & $\begin{array}{l}\text { Proactive Coping Subscale (PCS) } \\
\text { (Greenglass, 2002) }\end{array}$ & $\begin{array}{l}14-\text { item scale } \\
(14=\text { "not at all true" } \\
\text { to } 56=\text { "completely } \\
\text { true") }\end{array}$ & 42.71 & 5.18 & .73 \\
\hline
\end{tabular}


Table 2. Hierarchical Regression Analysis Evaluating Predictors of Successful Aging ( $=132)$

\begin{tabular}{|c|c|c|c|c|c|c|c|}
\hline Model/Variables & Adjusted $R^{2}$ & $\Delta R^{2}$ & $F_{d f}$ & $p$-value & $\beta$ & $t$-statistics & $p$-value \\
\hline Model 1 & .24 & .26 & $F_{5,126}=9.04$ & $<.001$ & & & \\
\hline Age & & & & & -.27 & -2.74 & $.007 *$ \\
\hline Sex (Female) & & & & & .17 & 2.09 & $.039 *$ \\
\hline Race (White) & & & & & -.04 & -.43 & .667 \\
\hline Residence (Community) & & & & & .13 & 1.28 & .201 \\
\hline Perceived Health & & & & & .33 & 4.29 & $<.001 *$ \\
\hline Model 2 & .50 & .27 & $F_{7,124}=19.93$ & $<.001$ & & & \\
\hline Age & & & & & -.12 & -1.39 & .168 \\
\hline Sex (Female) & & & & & .13 & 1.96 & .052 \\
\hline Race (White) & & & & & .04 & .51 & .610 \\
\hline Residence (Community) & & & & & .08 & .93 & .357 \\
\hline Perceived Health & & & & & .13 & 1.88 & .063 \\
\hline Self-Transcendence & & & & & .56 & 7.00 & $<.001 *$ \\
\hline Proactive coping & & & & & .06 & .75 & .455 \\
\hline Trimmed Model & .51 & .26 & $F_{6,125}=23.24$ & $<.001$ & & & \\
\hline Age & & & & & -.15 & -1.84 & .068 \\
\hline Sex (Female) & & & & & .12 & 1.90 & .060 \\
\hline Race (White) & & & & & .04 & .55 & .581 \\
\hline Residence (Community) & & & & & .07 & .87 & .410 \\
\hline Perceived Health & & & & & .13 & 1.96 & .052 \\
\hline Self-Transcendence & & & & & .59 & 8.34 & $<.001 *$ \\
\hline
\end{tabular}

Note. The $\Delta R^{2}$ in Model 2 and 3 were obtained by comparing the $R^{2}$ s of Model 2 and 3 to the $R^{2}$ of Model 1. 